\title{
HIV-1 coreceptors CCR5 and CXCR4 both mediate neuronal cell death but CCR5 paradoxically can also contribute to protection
}

\author{
$M_{\text {Kaul }}{ }^{\star, 1}, Q M^{2,3}$, KE Medders $^{1}$, MK Desai ${ }^{1}$ and SA Lipton ${ }^{1}$
}

The chemokine receptors CCR5 and CXCR4 serve, in addition to CD4, as coreceptors for human immunodeficiency virus-1 (HIV-1), and infection with HIV-1 can cause dementia. In brain-derived cells, HIV-1 envelope glycoprotein gp120 initiates a signaling cascade that involves $\mathrm{p} 38$ mitogen-activated protein kinase and leads to neuronal cell death. Using mixed neuronal/glial cultures from rats and mice genetically deficient in one or both HIV coreceptors, we show here that CCR5, CXCR4 or both can mediate HIV/ gp120 neurotoxicity depending on the viral strain. Paradoxically, we also found evidence for a CCR5-mediated neuroprotective pathway. We identify protein kinase Akt/PKB as an essential component of this pathway, which can be triggered by the CCR5 agonists macrophage inflammatory protein-1 $\beta$ and regulated-and-normal-T-cell-expressed-and-secreted. Moreover, these CCR5 ligands prevent neuronal cell death induced by stromal cell-derived factor-1, a CXCR4 agonist. Both neurons and glia coexpress CXCR4 and CCR5. $\mathrm{Ca}^{2+}$ imaging experiments demonstrate that engagement of CCR5 prevents CXCR4-triggered increases in intracellular free $\mathrm{Ca}^{2+}$. This finding suggests that CCR5 ligands can protect neurons at least, in part, by modulating CXCR4mediated toxicity through heterologous desensitization.

Cell Death and Differentiation (2007) 14, 296-305. doi:10.1038/sj.cdd.4402006; published online 14 July 2006

Chemokine receptors, such as CXCR4 (CD184) and CCR5 (CD195), serve as coreceptors with CD4 for human immunodeficiency virus-1 (HIV-1) envelope glycoprotein gp120, and mediate viral infection of lymphocytes, macrophages and microglia. ${ }^{1-3}$ As most transmitted viral strains prefer CCR5, congenital absence of this chemokine receptor offers significant protection from infection. ${ }^{4}$ If CCR5 is present, its endogenous ligands, namely 'macrophage inflammatory protein' (MIP)-1 $\alpha$ (CCL3), MIP-1 $\beta$ (CCL4) and 'regulatedand-normal-T cell-expressed-and-secreted' (RANTES, CCL5) can slow progression to AIDS. ${ }^{5}$ However, once HIV infection is established, CXCR4-preferring viruses can evolve, and these viruses usually herald progression to AIDS. ${ }^{6}$ Anywhere in the course of the disease, HIV-1 can cause neurological problems ranging from mild impairment of cognitive and motor skills to frank dementia. ${ }^{7-9}$ Although the neuropathological and neuropsychological alterations of HIVassociated dementia (HAD) have been described, the mechanism of disease-induced neuronal damage remains incompletely understood. In brain, HIV-1 productively infects primarily macrophages or microglia, but neurons suffer dendritic injury and synaptic loss, and eventually may die by apoptosis. ${ }^{7,10-13}$ The majority of viruses that have been isolated from brain prefer CCR5, whereas dual tropic and CXCR4-preferring variants seem to occur only occasion- ally. ${ }^{13,14}$ In any case, HIV-1/gp120 mediates infection or activation of macrophages and microglia. ${ }^{1-3,7,15}$ This leads to toxin production by these monocytic cells, which seems essential for a pronounced neurodegenerative effect. ${ }^{7,11,16-18}$ Indeed, we and others have observed earlier that gp120 neurotoxicity was virtually absent if microglia were either removed from mixed cerebrocortical cultures or inactivated. ${ }^{10,11,18,19}$ This finding strongly suggested a critical role for microglial HIV-1 coreceptors in the generation of neurotoxicity. ${ }^{20}$ Additionally, astrocytes and neurons possess CCR5 and CXCR4, consistent with the observation that under certain conditions chemokine receptors on these cells can also influence HIV-induced neuronal damage. ${ }^{7,13,21-25}$ Nevertheless, the exact pathologic function of CXCR4 and CCR5 in brain cells remains to be defined. Interestingly, brains from humans with HAD and transgenic mice expressing gp120 share many neuropathological features, including synaptic and dendritic damage, frank loss of neurons and activation of glia. ${ }^{7,26}$ These effects can be modeled in mixed neuronal/glial cerebrocortical cultures from rodents or humans in which purified or recombinant gp120 initiates neuronal injury and apoptosis. ${ }^{3,7,11,17,18,27,28}$

In order to further dissect the role of chemokine receptors in HIV/gp120-induced neurotoxicity, we used mixed neuronal/ glial cerebrocortical cultures prepared from wild-type (WT)

\footnotetext{
${ }^{1}$ Center for Neuroscience and Aging, Burnham Institute for Medical Research, 10901 North Torrey Pines Road, La Jolla, CA 92037, USA and ${ }^{2}$ Center for Blood Research, Harvard Medical School, 200 Longwood Avenue, Warren Alpert Building, Room 251, Boston, MA 02115, USA

${ }^{*}$ Corresponding author: M Kaul, Center for Neuroscience and Aging, Burnham Institute for Medical Research, 10901 North Torrey Pines Road, La Jolla, CA 92037, USA. Tel: 858-646-3100x3541; Fax 858-713-6273; E-mail: mkaul@burnham.org

${ }^{3}$ Current address: Department of Blood and Marrow Transplantation, M.D. Anderson Cancer Center, Houston, TX, USA

Keywords: HIV-1-associated dementia; neuroAIDS; neurodegeneration; apoptosis; immune activation; macrophages/microglia; HIV/gp120; chemokine receptors; CCR5; CXCR4; MIP-1 $\beta$; RANTES; knockout

Abbreviations: HIV-1, human immunodeficiency virus; MIP-1 $\beta$, macrophage inflammatory protein-1 $\beta$; RANTES, regulated-and-normal-T-cell-expressed-andsecreted; SDF-1, stromal cell-derived factor-1; MAPK, mitogen-activated protein kinase

Received 19.12.05; revised 24.5.06; accepted 09.6.06; Edited by G Melino; published online 14.7.06
} 
mice or rats, and mutant mice deficient in $\mathrm{CXCR} 4,{ }^{29} \mathrm{CCR} 5^{30}$ or both chemokine receptors. Our findings suggest that, depending on the viral strain, HIV/gp120 can utilize CCR5 or CXCR4 or both receptors for induction of neurotoxicity. In contrast, natural CCR5 ligands confer protection upon neurons against gp120 toxicity engaging either chemokine receptor by modulating $\mathrm{CXCR} 4-d e p e n d e n t$ processes via heterologous desensitization and involvement of AKT/PKB.

\section{Results}

Cerebrocortical cultures from rat were exposed for $24 \mathrm{~h}$ to gp120 (each at 200 pM) from different HIV-1 strains or, as control, to two chemokines (each at $20 \mathrm{nM}$ ) that are natural ligands for HIV coreceptors, as described previously. ${ }^{11}$ Subsequently, we assessed neuronal apoptosis and survival as indices of neurotoxicity as described in Materials and Methods. ${ }^{31}$ In neurotoxicity experiments, we routinely used immunostaining and pyknotic nuclear morphology to identify neurons and dead/apoptotic cells, respectively. Terminaldeoxynucleotidyl-transferase-mediated dUTP nick-end labeling (TUNEL) was used here in two out of three experiments for the control and gp120 ${ }_{\mathrm{SF} 2}$-treated sample to reveal DNA fragmentation as an additional sign of apoptosis besides nuclear morphology. The concentration of 200 pM for gp120 in all experiments of this study was chosen, because in pilot experiments smaller amounts $(20 \mathrm{pM})$ were more variable in producing neurotoxicity and higher concentrations (up to $2 \mathrm{nM}$ ) did not produce significantly more neuronal death during $24 \mathrm{~h}$ incubation (data not shown). The concentration of $20 \mathrm{nM}$ for chemokines was initially decided as a compromise between a physiological low nanomolar range and an excess for competition experiments with gp120. ${ }^{11,32}$ With the present approach, we observed that recombinant gp120 from CXCR4preferring virus (MN, IIIB isolates), CCR5-preferring virus (BaL, SF162), and dual tropic virus (SF2) all reduced neuronal survival in cerebrocortical cultures (Figure 1). Furthermore, stromal cell-derived factor-1 (SDF-1) $\beta$ (CXCL12), the physiological ligand of CXCR4, was confirmed as being neurotoxic, whereas CCR5-binding MIP-1 $\beta$ did not affect neuronal survival.

In order to further dissect the role of the two HIV coreceptors in gp120-induced neurotoxicity, we used a novel approach, preparing cerebrocortical cultures from mice genetically deficient in CXCR4, or CCR5, or both chemokine receptors, using WT as control. The cultures of each genotype appeared indistinguishable from one another based on immunostaining with cell type-specific markers for neurons, astrocytes, and microglia (Figure 2a). Furthermore, there were no significant differences with regard to the percentage of neurons, astrocytes, and microglia between WT and chemokine receptor-deficient cell cultures (Figure $2 b$ ).

Cerebrocortical cultures from WT mice were exposed for $24 \mathrm{~h}$ to recombinant gp120 (each at $200 \mathrm{pM}$ ) from CXCR4preferring virus (IIIB isolate), CCR5-preferring virus (SF162), and dual tropic virus (SF2) besides SDF-1 $\beta$ and MIP-1 $\beta$ (both at $20 \mathrm{nM}$ ). Subsequently, neuronal survival was assessed. All three gp120s and SDF-1 $\beta$ diminished neuronal survival, whereas MIP-1 $\beta$ did not (Figure 3a). Thus, our WT murine and rat cerebrocortical cells reacted in the same way when exposed to 'pathological' viral gp120s and physiological ligands of HIV coreceptors.

In cerebrocortical cultures from CXCR4-deficient mice compared to WT controls, however, we found diminished

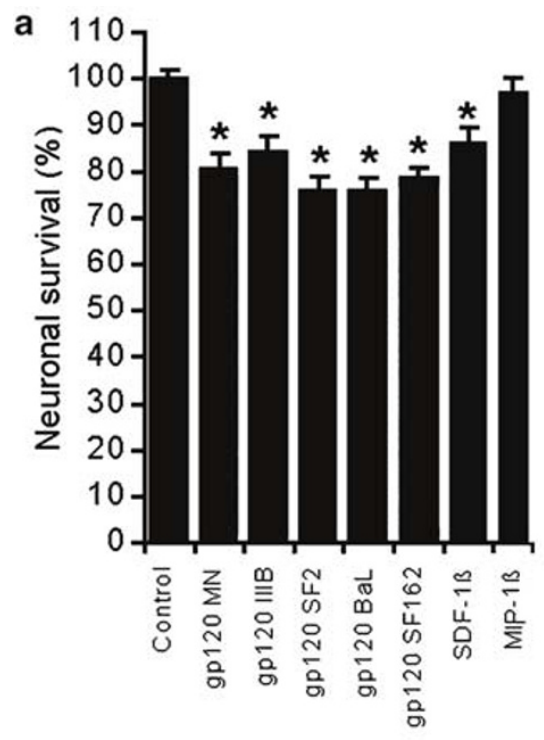

b

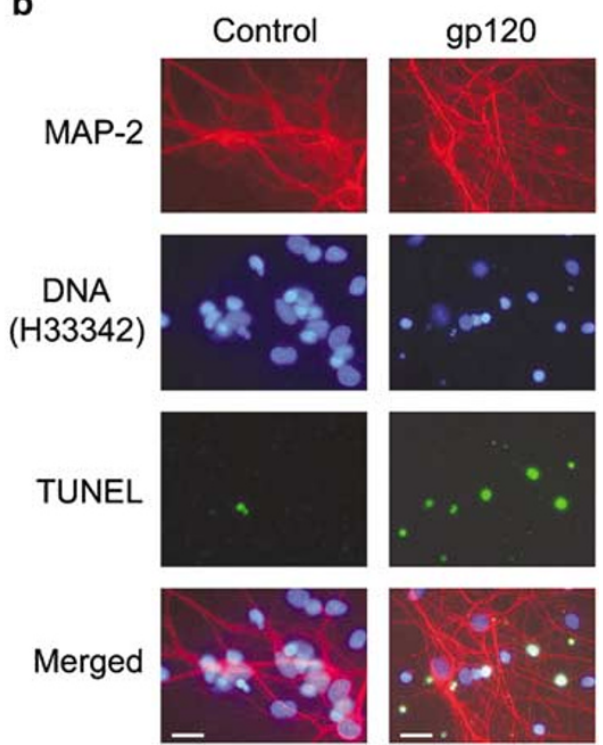

Figure 1 Envelope protein gp120 from CXCR4-preferring (MN, IIIB), CCR5-preferring (BaL, SF162), and dual tropic (SF2) HIV-1 strains (all at 200 pM concentration), and the CXCR4 ligand SDF-1 $\beta(20 \mathrm{nM})$ induce neuronal death in rat cerebrocortical cultures. In contrast, the CCR5 ligand MIP-1 $\beta(20 \mathrm{nM})$ does not impair neuronal survival. The control received BSA containing vehicle only ( $0.001 \%$ final concentration). Assessment of neuronal survival (a) and staining for neurons (MAP-2), nuclear DNA and TUNEL (b) were performed as described in Materials and Methods. Cells were exposed to recombinant gp120 of HIV-1 ${ }_{\mathrm{SF} 2}$ in the experiment shown in (b). An average of 7321 cells was counted per condition with duplicate or triplicate samples. Values in (a) are mean \pm S.E.M. $\left(n=3 ;{ }^{\star} P<0.001\right.$ compared to control by ANOVA followed by Fisher's PLSD post hoc test). Scale bar, $25 \mu \mathrm{m}$ 
a
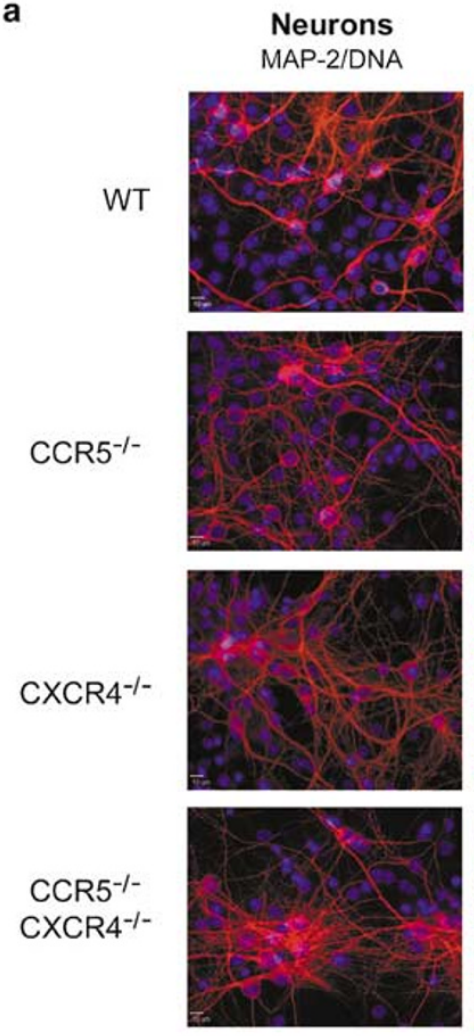

b

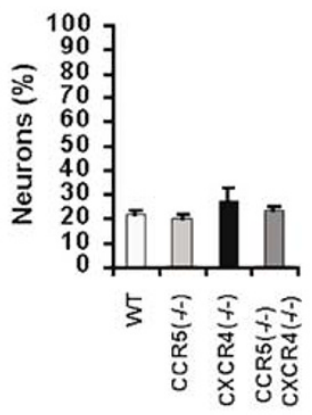

Astrocytes GFAPIDNA
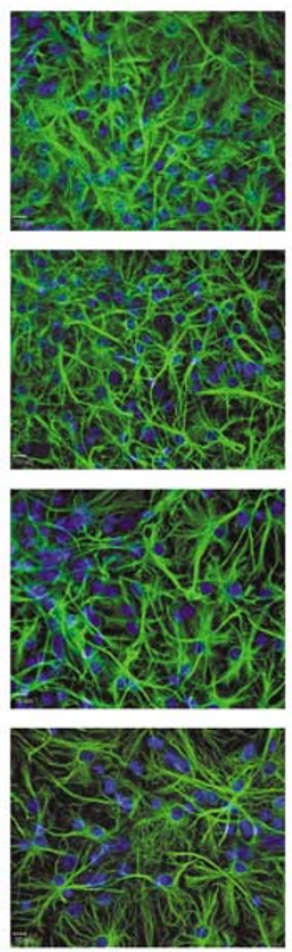

Microglia F $4 / 80 / D N A$
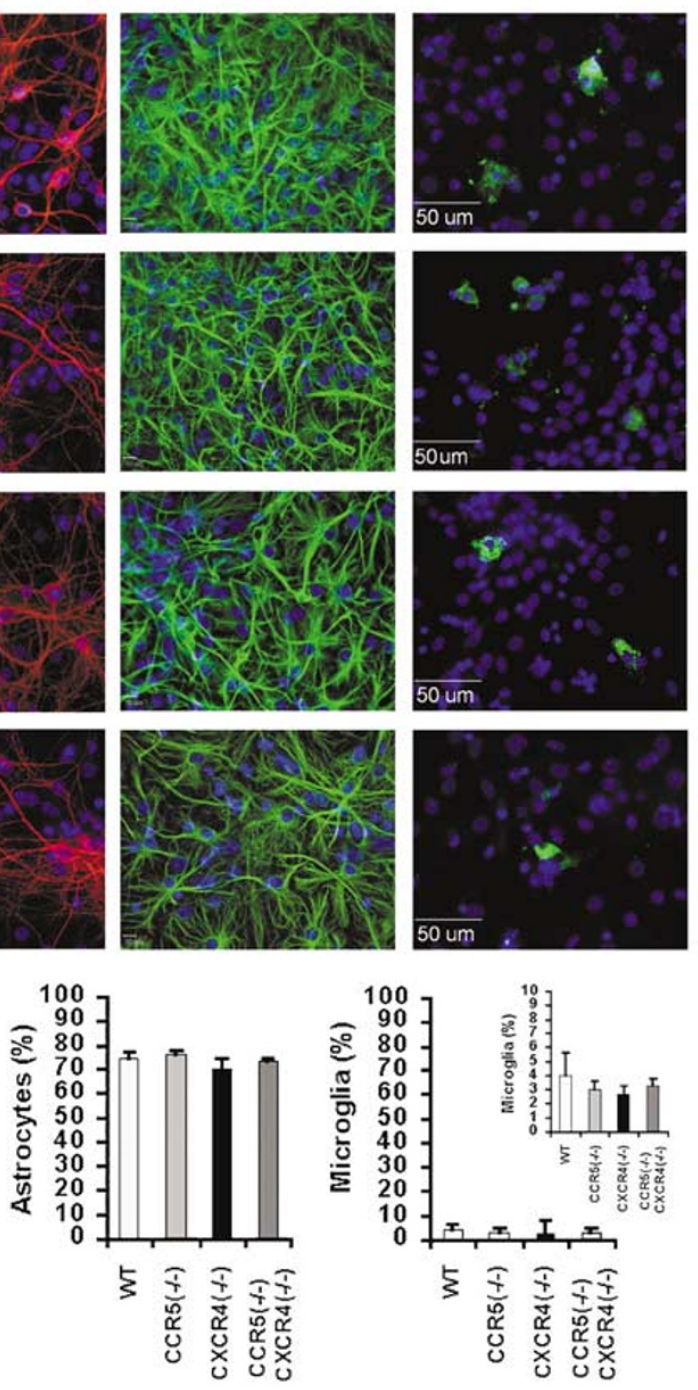

Figure 2 Murine cerebrocortical cultures derived from WT and chemokine receptor-deficient animals at day 18 in vitro. (a) Cultures from WT and chemokine receptordeficient mice were stained for the neuronal markers MAP-2 (red), astrocyte GFAP (green), microglial F4/80 (green), and the nuclear DNA stain Hoechst 33342 (blue) as indicated. All cerebrocortical cultures contained neurons, astrocytes, and microglia. Scale bar as indicated. (b) The percentage for each cell population was quantified based on the following cell numbers counted: 11759 (WT; $n=5$ ); 22715 (CCR5(-I-); $n=8$ ); 17067 (CXCR4(-I-); $n=7$ ); and 8385 (CCR5(-I-)CXCR4(-I-); $n=4$ ). Samples were duplicates or triplicates, and values are mean \pm S.E.M. No significant differences between the different genotypes could be detected for any cell type (ANOVA followed by Fisher's PLSD post hoc test)

neurotoxicity from gp120s that bind CXCR4 (Figure 3a and b). For example, neurotoxicity was largely abrogated in the case of gp120 from the CXCR4-preferring viral strain HIV-1 $1_{\text {IIIB }}$, as

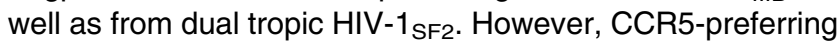

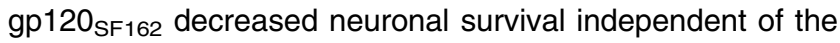
presence or absence of CXCR4, thus suggesting a neurotoxic activation of CCR5. As expected, the lack of CXCR4 completely prevented neuronal damage by SDF-1 $\beta$. As a control, CXCR4 deficiency did not alter neuronal vulnerability to the excitotoxin NMDA in comparison to WT (Figure 3c).

In CCR5-deficient cultures, we found that neurotoxicity of the CCR5-preferring gp120 ${ }_{\mathrm{SF} 162}$ was completely abrogated (Figure $3 a$ and b). Additional experiments with gp120 ${ }_{\text {SF162 }}$ showed that one allele of CCR5 was sufficient to mediate neurotoxicity. In contrast, after exposure to the CXCR4preferring strain gp120 IIIB, we surprisingly found increased neuronal damage in the CCR5 knockout (KO) cultures compared to WT. Similarly, in the case of dual tropic gp120 $0_{S F 2}$, neuronal demise significantly worsened when CCR5 was absent. Moreover, CCR5-deficient neurons were more sensitive to the toxic effect of the CXCR4 agonist SDF$1 \beta$, but not NMDA, compared to WT controls.

Next, we analyzed the effect of gp120 in cerebrocortical cultures lacking both CXCR4 and CCR5 chemokine receptors. The appearance of mixed neuronal/glial cultures from $\mathrm{CXCR}^{-1-} \mathrm{CCR}^{-1-}$ mice was indistinguishable from WT, heterozygous, or single-chemokine receptor $\mathrm{KO}$ controls (Figure $2 \mathrm{a}$ and b). Doubly chemokine receptor-deficient 

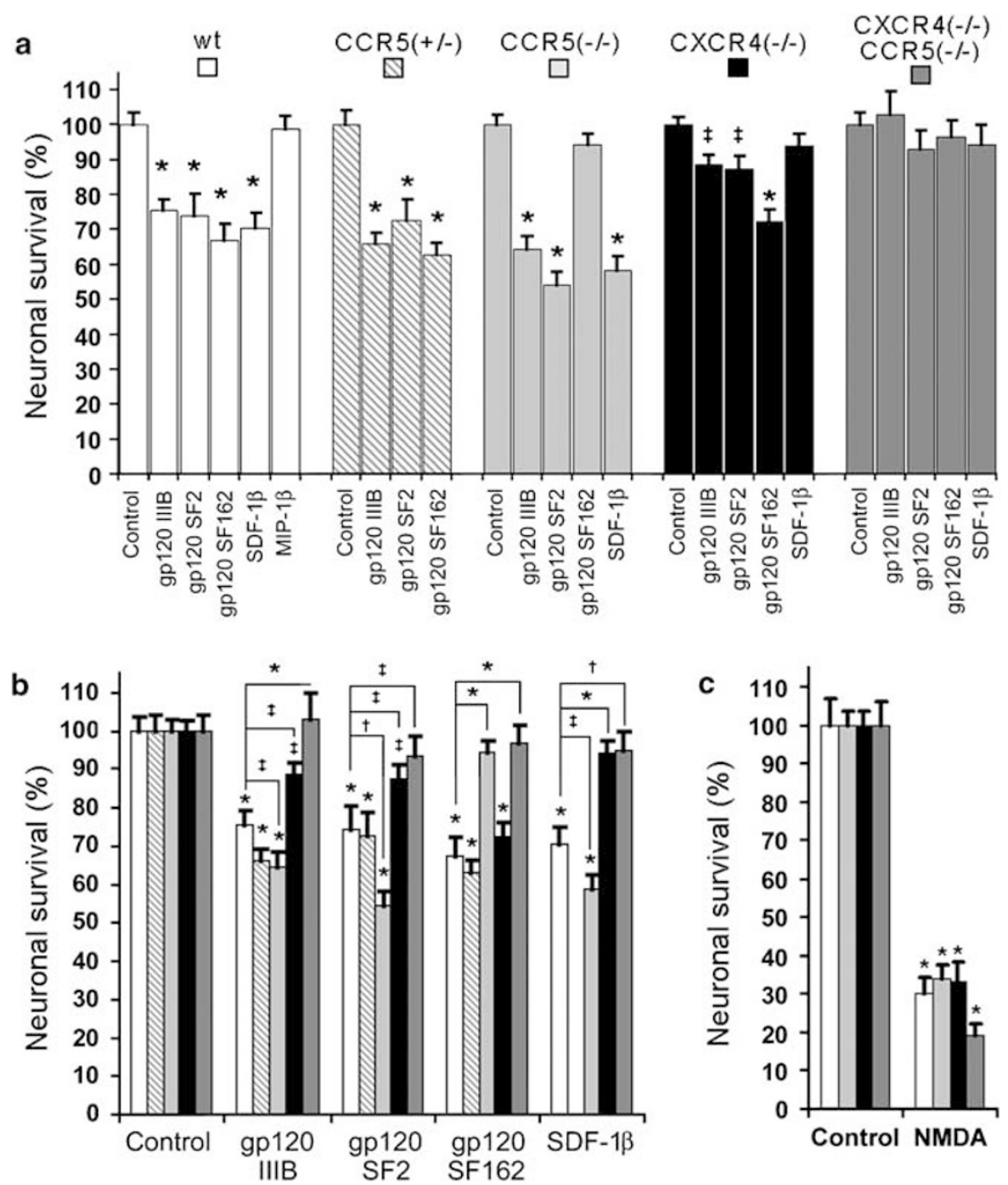

Figure 3 Neurotoxicity of gp 120 from different HIV-1 strains, SDF-1 $\beta$, and NMDA in WT and chemokine receptor-deficient murine cerebrocortical cells. (a-c) Cerebrocortical cultures were incubated for $24 \mathrm{~h}$ with gp120 $(200 \mathrm{pM})$, SDF-1 $\beta(20 \mathrm{nM})$ or $18 \mathrm{~h}$ after exposure to NMDA $(300 \mu \mathrm{M})$. Neuronal survival was assessed by microscopy. Results are shown in order of genotype in (a) and sorted by ligand (except for MIP-1 $\beta$ ) used for treatment in (b and $\mathbf{c}$ ). Average number of cells counted per condition (duplicate or triplicate samples): (a and b) WT, $6862(n=5)$; CCR5 ( + I-), $2658(n=3)$; CCR5(-l-), $15999(n=8)$; CXCR4(-l-), $10074(n=7)$; and CCR5(-l-)CXCR4(-l-), $5167(n=4)$; (c) $7929(n=3)$ per each genotype; ${ }^{\star} P<0.0005 ;{ }^{\dagger} P<0.005 ;{ }^{\ddagger} P<0.05$ by ANOVA compared to control, unless otherwise indicated by bars

neurons, however, were resistant to gp120 toxicity from $\mathrm{CCR}^{-}$, $\mathrm{CXCR} 4^{-}$, and dual tropic-preferring HIV-1 strains (Figure $3 a$ and $b$ ), although control experiments showed that $\mathrm{CXCR}^{-1-} \mathrm{CCR}^{-1-}$ neurons were as sensitive to NMDAinduced excitotoxicity as WT (Figure $3 c$ ).

Next, we intended to analyze the signaling pathway(s) mediating neuronal death downstream of HIV coreceptors. We chose to look at p38 mitogen-activated protein kinase (MAPK) as it is expressed in neurons, astrocytes and microglia and is involved in cellular stress response and microglial activation. ${ }^{33,34}$ First, we incubated cerebrocortical cultures with SB203580 (Calbiochem, La Jolla, CA, USA), a pharmacological inhibitor of p38 MAPK, $15 \mathrm{~min}$ before treatment with dual tropic gp $120_{\mathrm{SF} 2}$ or SDF-1 $\beta$. Neuronal survival was significantly reduced by both gp120 and SDF-1, but remained at control levels in the presence of the p38 inhibitor (Figure 4a). The reportedly more specific p38 inhibitor SD-282 (Scios, Freemont, CA, USA) manifested a similar protective effect when tested with gp120 (R Russo, M Kaul,
SA Lipton, unpublished data). ${ }^{35}$ As further evidence, we infected cerebrocortical cultures with an adenovirus encoding a dominant-interfering form of $\mathrm{p} 38 \mathrm{MAPK}$ or green fluorescent protein (GFP) as control 2 days before the cells were exposed to $\mathrm{HIV} / \mathrm{gp} 120_{\mathrm{SF}}$. The neurotoxic effect of the viral envelope protein was prevented by the dominant-interfering form of p38 MAPK, whereas GFP had no effect (Figure 4b).

In contrast to the neurotoxic findings with HIV/gp120 and the CXCR4 agonist SDF-1, the CCR5 ligands RANTES (CCL5) and MIP-1 $\beta$ (CCL4) afforded neuroprotection not only from gp $120^{11}$ but also from SDF-1 $\beta$ (Figure $5 \mathrm{a}$ ). The pivotal role of CCR5 for neuronal survival after exposure to gp120 was further supported by our finding that the CCR5 ligand RANTES did not prevent gp120-induced neuronal death in murine CCR5 KO cultures, whereas one allele of CCR5 was sufficient to convey full protection by RANTES (Figure $5 b$ ).

In order to identify potential signaling pathway(s) mediating protection of neurons downstream of HIV coreceptor CCR5, we decided to investigate the protein kinase Akt/PKB. The 

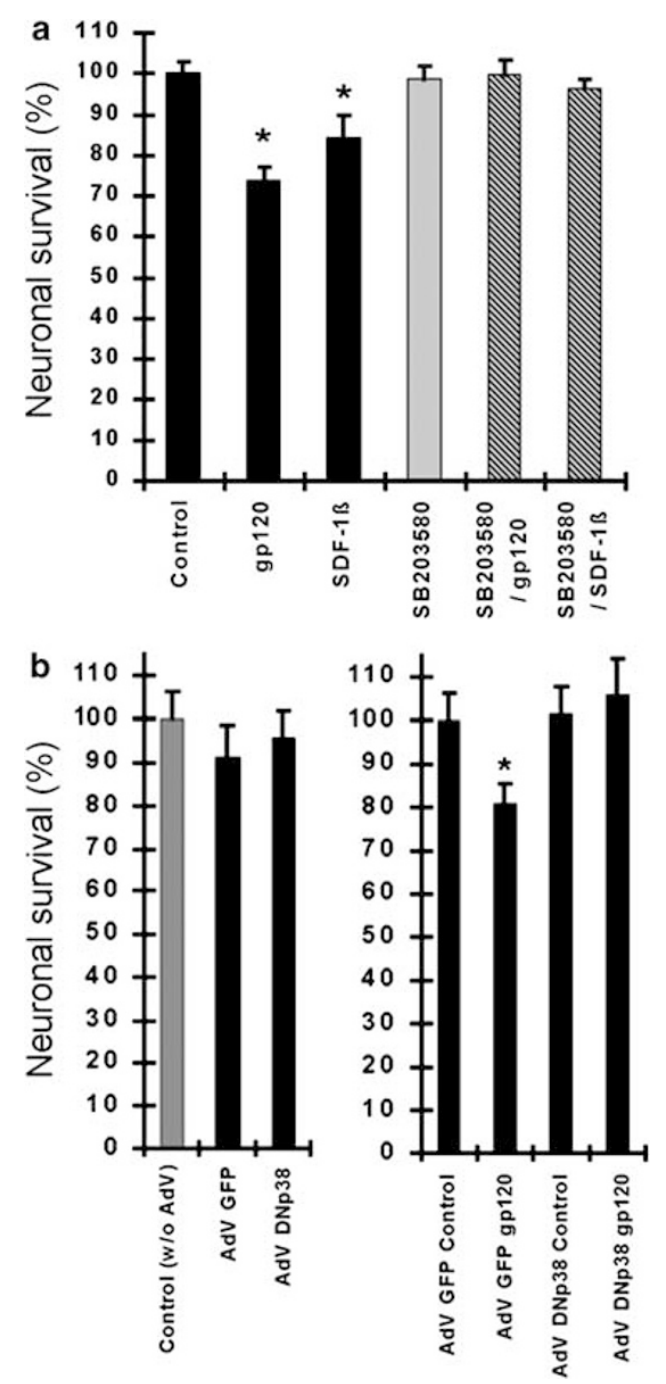

Figure 4 Inhibition of p38 MAPK protects neurons against HIV/gp120-induced neurotoxicity in rat cerebrocortical cultures. (a) SB203580 $(10 \mu \mathrm{M})$ abrogated neurotoxicity of HIV/gp120 (200 pM) and SDF-1. (b) Dominant-interfering p38 MAPK (AdV DNp38), but not control construct (AdV GFP), protected neurons from exposure to HIV/gp120. AdV vectors alone did not significantly affect neuronal survival. Average number of cells counted per condition with duplicate or triplicate samples: (a) $4615(n=3)$; (b) $4178(n=3)$; ${ }^{*} P<0.05$ by ANOVA

reason was that Akt was recently reported to protect against excitotoxic neuronal death, which is believed to contribute to HIV-1-induced neuronal injury. ${ }^{18,36-38}$ Thus, we infected cerebrocortical cultures with an adenovirus encoding a dominant-interfering form of Akt or WT Akt as control. After 2 days, the cultures were exposed to HIV/gp120 ${ }_{\mathrm{SF} 2}$ in the presence or absence of MIP-1 $\beta$. The dominant-interfering form of Akt abrogated the neuroprotective effect of the CCR5 agonist, whereas WT Akt had no effect (Figure 6c).

Next, we studied whether CCR5-mediated protection from toxicity of CXCR4 ligands could occur through direct interaction on neurons. For this purpose, we performed $\mathrm{Ca}^{2+}$ imaging experiments and immunofluorescence staining combined with deconvolution microscopy for neuronal markers and chemokine receptors. In $\mathrm{Ca}^{2+}$ imaging experiments, rat cerebrocortical cultures were exposed to SDF- $1 \beta$ and MIP-1 $\beta$, specific ligands for CXCR4 and CCR5, respectively, at the same concentrations used in the toxicity experiments. BSA was used as a control protein. Neurons were initially identified by their characteristic morphology using differential interference contrast in combination with an increase in intracellular free $\mathrm{Ca}^{2+}\left[\mathrm{Ca}^{2+}\right]_{i}$ in response to NMDA. We found that SDF$1 \beta(20 \mathrm{nM})$, but not MIP-1 $\beta(20 \mathrm{nM})$ or BSA $(144-432 \mathrm{nM})$, evoked an increase in neuronal $\left[\mathrm{Ca}^{2+}\right]_{\mathrm{i}}$ (Figure $5 \mathrm{~d}$ ). However, application of MIP- $1 \beta$ before SDF- $1 \beta$ suppressed this $\left[\mathrm{Ca}^{2+}\right]_{\mathrm{i}}$ response (Figure $5 d$, middle panel). BSA did not display this effect (Figure 5d, right panel), suggesting that CCR5 specifically modulated CXCR4-mediated responses through heterologous desensitization.

Furthermore, triple immunofluorescence and deconvolution microscopy revealed that rat cerebrocortical neurons stained with the neuron-specific marker MAP-2 as well as for CCR5 and CXCR4 chemokine receptors, which also localized to non-neuronal/glial cell types (Figure 6a-d). Quantitation by cell counting showed that $90.7 \pm 2.7 \%( \pm$ S.E.M. $)$ of the cells were positive for CXCR4 and CCR5. $99.2 \pm 0.8 \%$ of the neurons, $88.1 \pm 3.2 \%$ of the glial cells, and $100 \%$ of the microglia, stained for both chemokine receptors, although with wide-ranging signal intensities and various cellular localizations. Staining for both receptors was found either to be intense and spread out throughout the cell body (Figure 6a and d) or strongly concentrated in the perinuclear space (Figure $6 b-d$ ) Finally, $1.9 \pm 0.6 \%$ of cells displayed only CXCR4 and $6.9 \pm 2.8 \%$ appeared to possess only CCR5.

\section{Discussion}

The present study shows that recombinant viral envelope proteins from CCR5-preferring, CXCR4-preferring, or dual tropic HIV-1 strains can all induce neuronal injury and death in mixed neuronal/glial cerebrocortical cultures from rodents. This finding in combination with the observations made in the different chemokine receptor-deficient cerebrocortical cultures strongly suggest that both HIV coreceptors, that is, CCR5 and CXCR4, can contribute to neuronal injury and death triggered by HIV/gp120. A model of the role of CCR5 and CXCR4 in neurotoxicity of HIV-1 gp120 and SDF-1, and the protective function of CCR5, is proposed in Figure 7. The additional finding that deficiency in CCR5 or CXCR4 significantly decreased neurotoxicity by CCR5- or CXCR4-preferring gp120s, respectively, resembles the specificity of HIV coreceptors in human cells and thus suggests the rodent system as a suitable model for these chemokine receptor studies. ${ }^{1,2}$

HIV coreceptors in the brain are expressed by microglia, astrocytes, and neurons, ${ }^{7,21,22,24}$ and we showed here that the receptors can apparently be coexpressed in most of these cells. However, only microglia possess also CD4, which strongly favors the interaction of gp120 with CCR5 and CXCR4. Moreover, we and others have observed earlier that gp120 neurotoxicity was completely abrogated if microglia were either removed from mixed cerebrocortical cultures or inactivated. ${ }^{10,11,18-20}$ All these findings support a critical role for microglial HIV-1 coreceptors in the generation of neurotoxicity (Figure 7a).

In contrast to HIV-1/gp120, chemokines do not require CD4 for interaction with HIV chemokine coreceptors, and our 

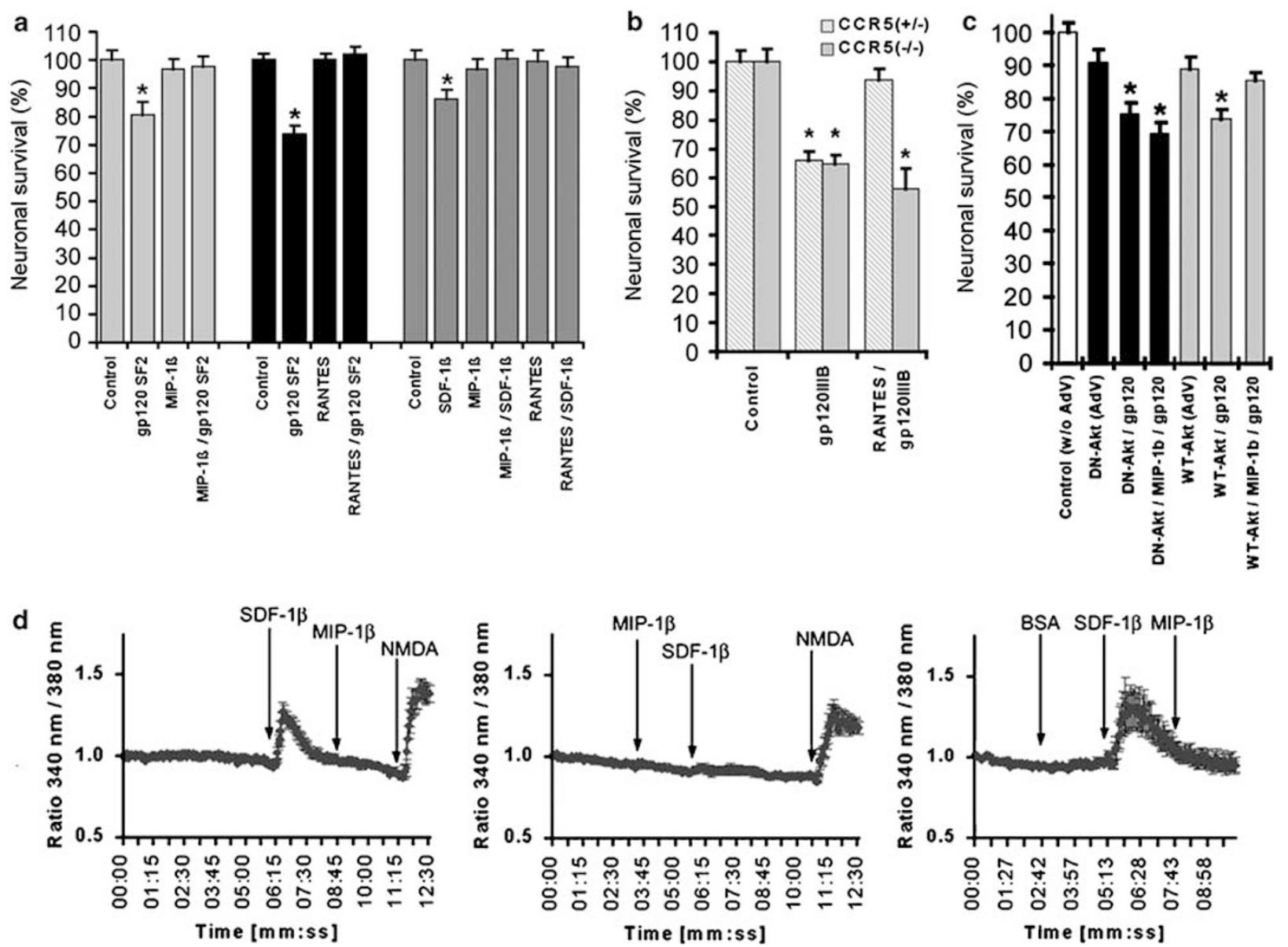

Figure 5 Effects of the chemokine receptors CXCR4/CCR5 and their natural ligands on neurotoxicity induced by HIV/gp120 and SDF-1. (a) CCR5 agonists, MIP-1 $\beta$ or RANTES (20 nM each), protected rat cerebrocortical neurons against neurotoxicity of HIV-1/gp120 (200 pM) and SDF-1 (20 nM). An average number of 3695 cells was counted per condition with duplicate or triplicate samples. Values are mean \pm S.E.M. $\left(n=3 ;{ }^{*} P<0.04\right.$ by ANOVA compared to control or $\beta$-chemokine-treated samples). (b) The CCR5 ligand RANTES protected murine cerebrocortical neurons from HIV/gp120-induced toxicity only if CCR5 receptors were present as shown here for CCR5 ( $+/-$ ) versus CCR5 $(-I-)$ cerebrocortical cultures. An average of 6146 cells was counted per condition with duplicate or triplicate samples. Values are mean + S.E.M. $(n=4$; ${ }^{*} P<0.0001$ by ANOVA compared to control). (c) CCR5 ligand via activation of Akt protects rat cerebrocortical neurons against HIV/gp120-induced neurotoxicity. Dominantinterfering Akt (DN-Akt), but not WT Akt (WT-Akt), abrogated neuroprotection by the CCR5 ligand MIP-1 $\beta$ ( $20 \mathrm{nM})$. An average of 4865 cells was counted per condition with duplicate or triplicate samples. ( $n=4 ;{ }^{*} P<0.005$ by ANOVA compared to adenovirus (AdV) alone). AdV vectors alone did not significantly affect neuronal survival. (d) MIP-1 $\beta$ suppresses SDF-1 $\beta$-induced increase in $\left[\mathrm{Ca}^{2+}\right]_{\mathrm{i}}$. Fura-2-loaded rat cerebrocortical neurons were exposed to SDF-1 $\beta$, MIP- $1 \beta$ (both at $20 \mathrm{nM}$ final concentration), BSA ( $144 \mathrm{nM}$ final concentration) or NMDA ( $1 \mu \mathrm{M}$ final concentration), as indicated by arrows. The change in the fluorescence ratio signal ( $340 / 380 \mathrm{~nm})$ was recorded over time as described in Materials and Methods. Averaged traces of $30-40$ cells \pm S.E.M. are shown for one representative out of four experiments

studies on physiological chemokines revealed an important difference between CXCR4 and CCR5. We found that natural ligands for CCR5, such as MIP-1 $\beta$ and RANTES, per se did not affect neuronal survival but abrogated gp120-induced neuronal death, whereas the natural agonist of CXCR4, SDF1 , was by itself neurotoxic. ${ }^{11}$ Our finding that SDF-1 toxicity was prevented in CXCR4-deficient cerebrocortical cultures confirmed the fact that, at least in our experimental system, this $\alpha$-chemokine induced neuronal damage specifically via its physiological receptor.

However, in a surprising and paradoxical manner, we observed in the current study that physiological CCR5 ligands could also ameliorate or prevent the neurotoxic effects of CXCR4 stimulation by SDF-1, the receptor's exclusive natural ligand. Moreover, triple-immunofluorescence staining revealed almost $100 \%$ coexpression of both chemokine receptors on neurons in our culture system, and the selective CCR5 ligand MIP-1 $\beta$ suppressed CXCR4-mediated increases in neuronal $\left[\mathrm{Ca}^{2+}\right]_{\mathrm{i}}$. Taken together, these findings strongly suggest that the neuroprotective effect of CCR5binding MIP-1 $\beta$ and RANTES involves heterologous desensitization of CXCR4 receptors on neurons (Figure 7). However, our experimental findings cannot rule out that a similar desensitization in astrocytes also indirectly contributes to neuroprotection. This possibility seems reasonable as activation by SDF-1 of astrocytic CXCR4 can induce a potentially neurotoxic glutamate release from the cells. ${ }^{11,25}$ In the case of HIV-1/gp120, the neuroprotective effect of CCR5 ligands could be explained by interference with HIV coreceptors on microglia and macrophages, causing direct competition with gp120 for CCR5 binding. However, the fact that HIV coreceptors in the brain are also expressed on astrocytes 
a

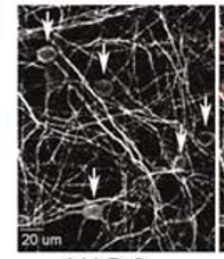

MAP-2

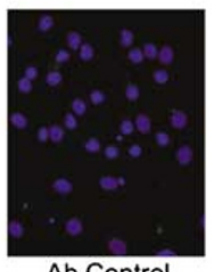

Ab Control DNA

b

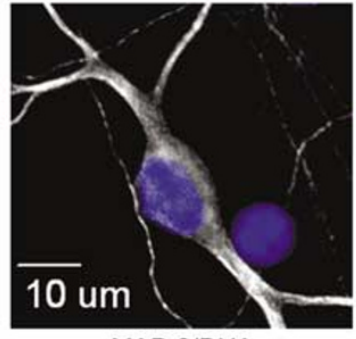

MAP-2/DNA
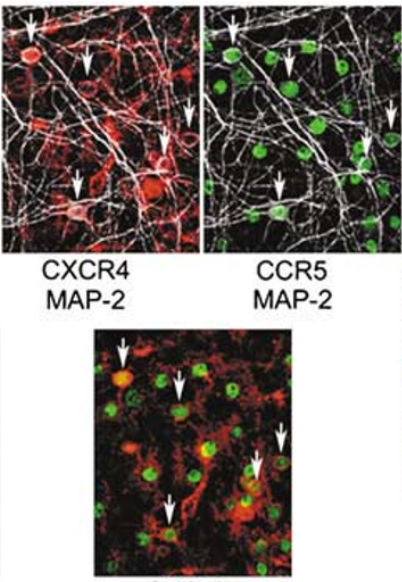

CXCR4

CCR5

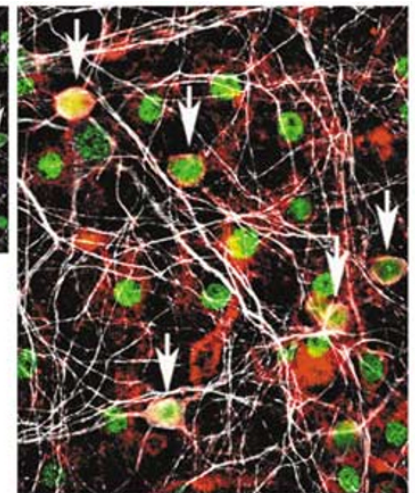

CXCR4/CCR5

MAP-2

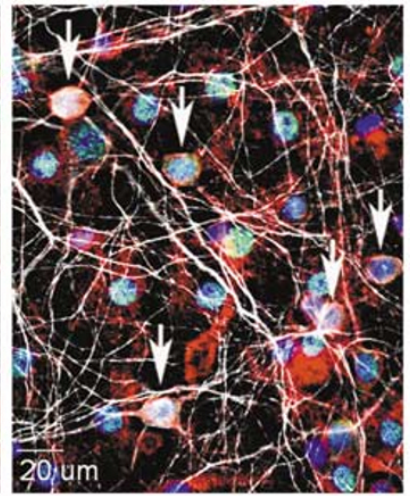

CXCR4/CCR5

MAP-2/DNA

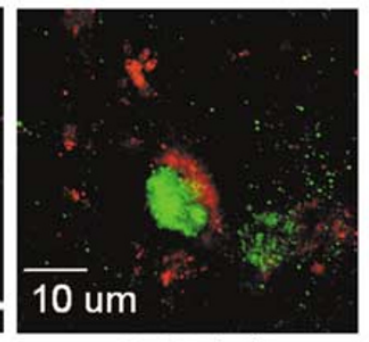

CXCR4(red) CCR5 (green)

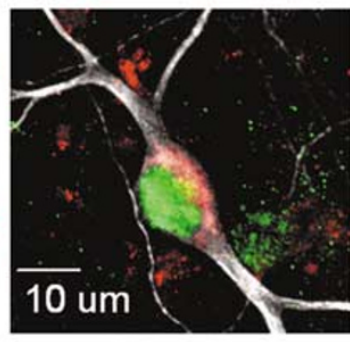

CXCR4/CCR5 MAP-2

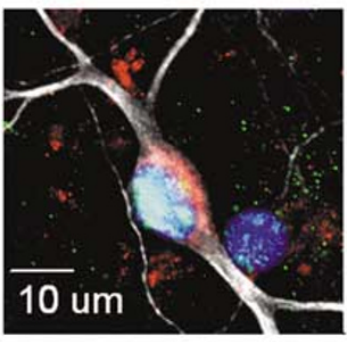

CXCR4/CCR5 MAP-2/DNA
C

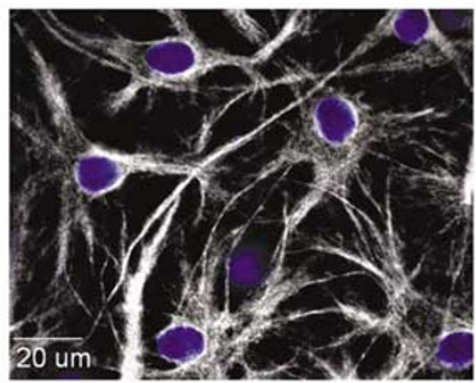

GFAP/DNA

d

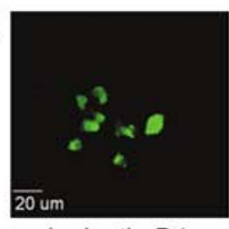

Isolectin B4

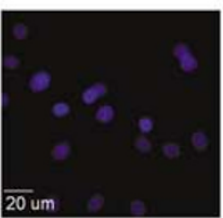

DNA

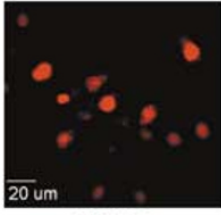

CCR5

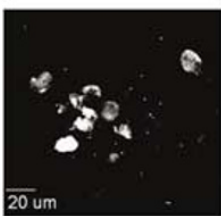

CXCR4

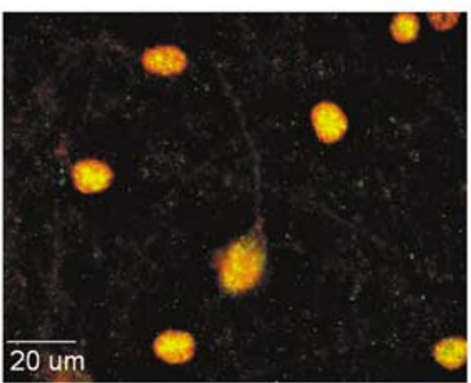

CXCR4 (red) CCR5 (green)

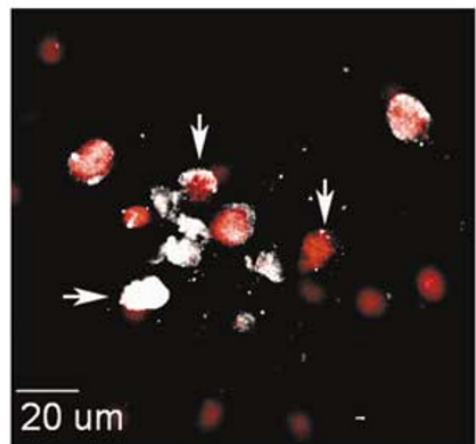

CXCR4

CCR5

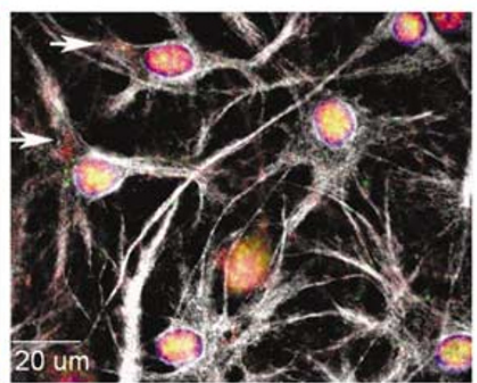

CXCR4/CCR5

GFAP/DNA

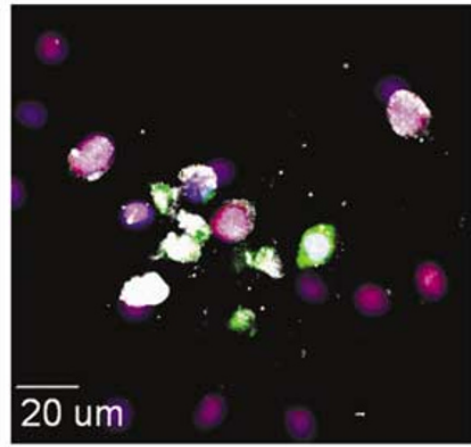

CXCR4/CCR5 Isolectin B4/DNA 
and neurons, ${ }^{7,21,22,24}$ and that the neurotoxicity of SDF-1 does not depend on microglial activation, ${ }^{11,25}$ yet is blocked by CCR5 ligands, suggests that CCR5-dependent neuroprotection can also be mediated by cell types other than microglia, such as astrocytes and neurons themselves. Indeed, our study provides for the first time a potential explanation for neuroprotection by natural CCR5 ligands via heterologous desensitization of CXCR4 directly on neurons (Figure 7b). Such desensitization has also been observed in B- and T-lymphocytes. ${ }^{39,40}$ Interestingly, we and others have observed that MIP-1 $\beta$ and RANTES also reduce neuronal death owing to direct excitotoxic insult by NMDA, which is also consistent with a direct effect of these CCR5 ligands on neurons. ${ }^{36,41}$

Our neurotoxicity experiments on cerebrocortical cultures from CCR5 KO mice demonstrate a pivotal role for this receptor in neuroprotection. Interestingly, the CCR5 ligands
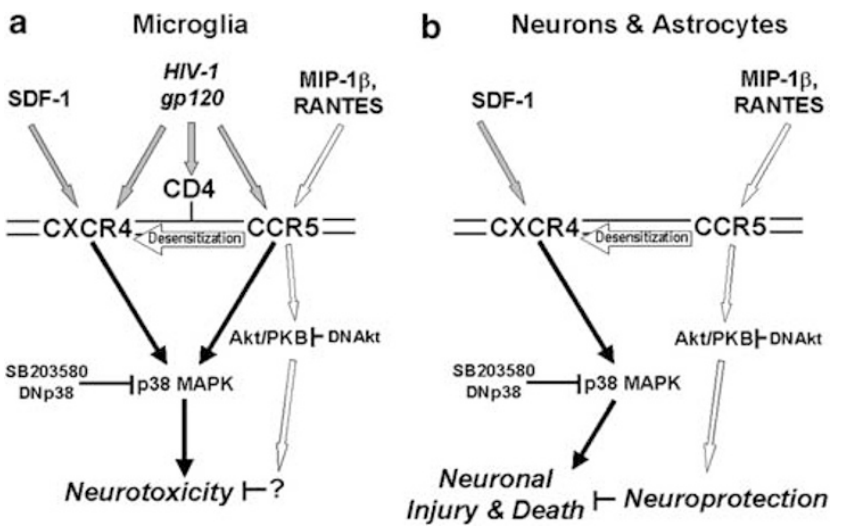

Figure 7 Proposed model for the role of CCR5 and CXCR4 in neurotoxicity of HIV-1 gp120 or SDF-1, and the protective function of CCR5. Filled arrows indicate toxic, whereas open arrows represent protective pathways. (a) Depending on whether a given gp120 belongs to a CCR5-preferring or CXCR4-preferring, or dual tropic HIV-1, it interacts with microglia/macrophages using one or both of the HIV coreceptors in conjunction with CD4. Subsequently, microglia/macrophages produce neurotoxicity, presumably involving the protein kinase p38MAPK. (b) Neurons and astrocytes express the HIV coreceptors, but lack CD4, and therefore are less likely to interact with gp120. However, chemokines do not require CD4 for binding to CCR5 or CXCR4, thus SDF-1 might directly interact with all three cell types to generate neurotoxicity, again involving p38MAPK. The CCR5 ligands MIP. $1 \beta$ and RANTES can also interact with all three cell types and might prevent gp120induced neurotoxicity of microglia by either competing with the viral envelope protein for binding to CCR5, or desensitizing CXCR4, or a conjunction of both effects. In addition, the $\beta$-chemokines might also desensitize CXCR4 in neurons and astrocytes and thereby abrogate both a direct and an indirect toxic effect of SDF-1. The neuroprotective effect mediated by CCR5 requires the activation of the protein kinase Akt, but it is not known whether the kinase is involved in the desensitization of CXCR4 and if it directly inhibits microglial neurotoxicity. Akt and p38MAPK are expressed in all cell types involved, and their activity can be inhibited by dominant negatively interfering mutants (DN) or pharmacological tools (SB203580). Blockade of p38MAPK activity prevents neurotoxicity of gp120 and SDF-1, but inhibition of Akt disrupts CCR5-mediated neuroprotection
RANTES and MIP $-1 \alpha / \beta$ have been found to be highly expressed in cerebrospinal fluid (CSF) of neurocognitively intact HIV-infected individuals, whereas the same chemokines were drastically diminished in the CSF of cognitively impaired AIDS patients. ${ }^{42}$ These findings are consistent with the notion that endogenous CCR5 ligands may offer neuroprotection in the setting of neuroAIDS.

Our observation that CCR5 deficiency increased CXCR4mediated toxicity of SDF-1 and some gp120s (IIIB and SF2) led us to wonder whether endogenous neuroprotective CCR5 ligands are present at baseline. However, small amounts of these ligands may not suffice to prevent neuronal death in the presence of additional exogenous neurotoxic gp120 or SDF1. Any small amount of CCR5 ligands would, of course, also no longer have any effect in the absence of CCR5. However, we were unable to detect any protein of endogenous CCR5 ligands in our cerebrocortical cultures ( $\mathrm{M}$ Kaul and KE Medders, unpublished). Alternatively, it has been reported that even without CCR5 ligand the receptor's presence seems to influence the expression of CXCR4 on the cell surface. ${ }^{43}$ Therefore, it is conceivable that the absence of CCR5 per se influenced the response of the cerebrocortical cultures to CXCR4 binding factors. It remains to be elucidated whether or not the absence of one HIV coreceptor modulates the physicochemical properties of the other receptor, such as the binding affinity for ligands. Besides changes in expression level, heterodimerization and complete or partial desensitization could provide potential explanations for the increased CXCR4-dependent toxicity in the absence of CCR5.

Mechanistically, we found that the neuroprotective effect of CCR5 activation was abrogated by a dominant-interfering form of Akt, whereas WT Akt had no effect. Additionally, the neurotoxic effect of dual tropic HIV/gp120 $\mathrm{SF}_{\mathrm{S} 2}$, which engages both types of chemokine receptor, was prevented by either pharmacological inhibition or a dominant-interfering form of p38 MAPK. These findings indicated that the balanced activities of these two protein kinases play an important role in preventing neuronal injury and death upon exposure to HIV/gp120 (or SDF1) in the presence of CCR5 ligands. As both protein kinases are expressed in neurons, astrocytes and microglia, ${ }^{33,34,44}$ we cannot currently determine whether the balanced activities of the two kinases in neurons alone suffice to prevent cell death. However, the neurotoxicity of both gp120 and SDF-1 has been found to be mediated in part by an excitotoxic component that involves neuronal p38 MAPK. ${ }^{11,18,25,36}$ In addition, neuronal Akt has been shown to provide protection against excitotoxic insult. $^{38}$ Therefore, it is possible that CCR5 activation acts to balance the activity of both kinases and thus provides neuroprotection, either directly via action on neurons, indirectly via other, glial cell types, or a combination of both.

Taken together, our study reveals a functional paradox for the two HIV chemokine coreceptors. CXCR4 plays an

Figure 6 CXCR4 and CCR5 are coexpressed in rat cerebrocortical neurons and glia. Triple-immunofluorescence staining for chemokine receptors and neuron-specific marker MAP-2 (a, b), or astrocyte GFAP (c), or labeling of microglia with isolectin B4 (d) was performed as described in Materials and Methods, and observed by deconvolution microscopy. For quantitation, 1023 cells were counted in three representative out of 11 independently stained cell preparations; $90.7 \pm 2.7 \%$ ( \pm S.E.M.) of the cells were positive for CXCR4 and CCR5; $99.2 \pm 0.8 \%$ of the neurons; and $88.1 \pm 3.2 \%$ of the glial cells, but $100 \%$ of the microglia stained for both chemokine receptors, although with various intensities and cellular localizations. Arrows indicate CCR5-CXCR4 double-positive neurons in (a), staining in astrocyte cell bodies in (b), and a range of staining intensities in microglia in (d) 
essential role in brain development and neuronal function; ${ }^{29,45,46}$ yet, our findings indicate that CXCR4-mediated signaling can also trigger neuronal cell injury and death, at least in part via activation of p38 MAPK. This is true of both the specific CXCR4 agonist SDF-1 as well as HIV-1 gp120s that bind to this chemokine receptor. On the other hand, ligands that bind to the second major HIV-1 coreceptor, CCR5, including the agonists RANTES and MIP-1 $\beta$, confer neuroprotection by activating an Akt-dependent signaling pathway. Paradoxically, CCR5-preferring gp120s, such as gp120 ${ }_{\text {SF162 }}$, induce neuronal death. Therefore, we conclude that interaction with CCR5 and CXCR4 can either protect or harm the nervous system, depending on the exact context, ligand characteristics, and resultant signaling pathway. Mechanisms, such as heterologous desensitization, may play a critical role in this outcome (Figure 7). Importantly, our findings strongly suggest that in the absence of neuroprotective CCR5 ligands, inactivation of both CXCR4 and CCR5 chemokine receptors might be necessary to fend off the neurotoxicity of HIV-1.

\begin{abstract}
Materials and Methods
Chemokine receptor KO mice. All mice were on a mixed C57BI/ $6 \times \mathrm{SV} 129$ genetic background. We previously generated and described heterozygous CXCR4 $\mathrm{KO}$ mice. ${ }^{29}$ CCR5-deficient mice ${ }^{30}$ were obtained from Jackson Laboratories. The two lines were cross-bred in order to generate animals deficient for both CXCR4 and CCR5 as well as WT controls and animals deficient in only one of the two HIV coreceptors. As all mice shared the same genetic background and WT littermates were used as controls, strain differences cannot account for the observations made here in the neurotoxicity experiments. CXCR4-deficient strains were maintained as heterozygous animals because of perinatal lethality of the homozygous phenotype ${ }^{29}$ homozygous CXCR4-deficient embryos for cell culture were obtained between day E14.5 and E16. Genotyping was performed on DNA obtained from tail biopsies using published PCR protocols (Jackson Laboratories). ${ }^{29}$
\end{abstract}

Rodent mixed neuronal/glial cerebrocortical cultures. Mouse cerebrocortical cultures from littermate WT and KO animals were prepared from embryos, as described previously, except that no cytostatic drugs were used. ${ }^{47-49}$ Rat cultures, which had been studied previously and characterized, were used for experiments where only WT for both chemokine receptors was required. ${ }^{11,31}$ Both types of cultures contained neurons, astrocytes, and microglia, and their composition has been described in detail. ${ }^{47,48}$ Although the $\mathrm{CXCR} 4^{-1-}$ phenotype is lethal at approximately $\mathrm{E} 18$, the isolated cerebrocortical cells survived well in vitro. Double KO embryos for cerebrocortical cultures were generated by crossbreeding mice deficient in both CXCR4 and CCR5 (in the case of CXCR4, using exclusively heterozygotes for breeding). Generally, cerebrocortical cell cultures were used for experiments after 17 days in vitro as described previously. 47,48

\begin{abstract}
Adenoviral vectors and infection of cerebrocortical cells. Hemagglutinin (HA)-tagged adenoviral constructs (AdV) for the WT and dominant-interfering forms of Akt were kind gifts of Dr. K Walsh. ${ }^{50} \mathrm{~A}$ dominantnegative form of $\mathrm{p38}$ MAPK and GFP control vector were kindly provided by Dr. J Han ${ }^{51,52} \mathrm{AdVs}$ were amplified and titrated following standard methods. To infect cerebrocortical cultures with minimal toxicity, AdVs were used at a multiplicity of infection (MOI) of 10 , as described recently. ${ }^{38}$ Neurotoxicity experiments were performed $48 \mathrm{~h}$ after infection with $\mathrm{AdVs}$, and the presence of transduced proteins was assessed by immunofluorescence. ${ }^{38}$
\end{abstract}

Exposure to toxins. Recombinant gp120 from different HIV-1 strains, representing CCR5-preferring, CXCR4-preferring, or dual tropic viruses, were obtained from the NIH AIDS Research and Reference Reagent Program or kindly provided by Genentech. Chemokines were purchased from R\&D Systems (Minneapolis, MN, USA; MIP-1 $\beta$, SDF-1), PeproTech (Rocky Hill, NJ, USA; MIP$1 \beta$, SDF-1) or Endogen (Endogen/Pierce Biotechnology Inc., Rockford, IL, USA; RANTES). Recombinant RANTES and gp120 from HIV-1 BaL, SF162, IIIB, and MN were obtained as carrier-free preparations, and gp120 of HIV-1SF2 contained no more than $2 \mathrm{ng} / 100 \mu \mathrm{g}$ of contaminating bovine serum protein or protein $\mathrm{G}$. Stocks of gp120 from HIV-1 BaL, IIIB and MN were in PBS, whereas the envelopes of HIV1 SF2 and SF162 were provided in citrate buffer. SDF-1 and MIP-1 $\beta$ preparations contained $50 \mu \mathrm{g} \mathrm{BSA} / 1 \mu \mathrm{g}$ chemokine as carrier when obtained from R\&D Systems, but were carrier-free when purchased from PeproTech. All recombinant chemokines and HIV-1/gp120s were reconstituted at micromolar concentrations to be in $0.1 \%$ BSA in PBS at one to 500 times the final concentration. HIV-1/gp120s were usually reconstituted directly before experiments, whereas chemokines were stored in aliquots at $-80^{\circ} \mathrm{C}$ until use. The original preparations of recombinant SDF-1, MIP$1 \beta$, and gp120 of HIV- $1 \mathrm{BaL}$ and SF162 were not endotoxin-free. Owing to dilution of the original preparations $(1: 18500-1: 22900$ for gp120s and $1: 5000-1: 6400$ for chemokines) required to obtain the final experimental concentration of any given recombinant protein, endotoxin was below $0.14 \times 10^{-3} \mathrm{EU} / \mathrm{ml}$ for all experiments with gp $120_{\mathrm{SF} 162}$ and below $0.1 \times 10^{-4} \mathrm{EU} / \mathrm{ml}$ for SDF-1, MIP-1 $\beta$ and gp $120_{\mathrm{BaL}}$. For experiments, cultures were transferred into prewarmed Earle's balanced salt solution (EBSS) containing $1.8 \mathrm{mM} \mathrm{Ca}^{2+}$ and $5 \mu \mathrm{M}$ glycine but no $\mathrm{Mg}^{2+}$. The cells were then incubated for $24 \mathrm{~h}$ in the presence or absence of gp120, chemokines, or combinations thereof as described. ${ }^{11}$ Controls received the BSA vehicle alone $(0.001 \%$ final concentration). As a positive control for neuronal cell death, cultures were exposed for $20 \mathrm{~min}$ to the excitotoxin $N$-methyl-D-aspartate (NMDA, $300 \mu \mathrm{M}$ ) followed by overnight incubation (18 h). ${ }^{31}$

Assessment of neurotoxicity. The number of neurons was quantified by immunostaining for the neuron-specific markers microtubule-associated protein-2 (MAP-2) and NeuN, and apoptotic nuclei were identified morphologically after staining nuclei with the DNA dyes Hoechst 33342 or propidium iodide. ${ }^{11,12}$ In two out of three experiments shown in Figure 1 and in seven out of twenty-seven experiments performed with the different WT and chemokine receptor-deficient murine cerebrocortical cultures, TUNEL (Apoptosis Detection System/Fluorescein, Promega, Madison, WI, USA) was applied to detect fragmented nuclear DNA in apoptotic nuclei. ${ }^{11,31}$ Neuronal survival was calculated from the percentage of neurons remaining after subtraction of those that had undergone apoptosis. Three to eight independent experiments were performed with each genotype.

Immunofluorescence staining of chemokine receptors. Rat cerebrocortical cultures were equilibrated for $30 \mathrm{~min}$ in EBSS containing $1.8 \mathrm{mM}$ $\mathrm{Ca}^{2+}$ and $5 \mu \mathrm{M}$ glycine but no $\mathrm{Mg}^{2+}$ and neurons discerned from glia by immunostaining as described above for the neurotoxicity experiments. Primary antibodies included two rabbit anti-CXCR4 IgGs (1:500 dilution, Chemicon, Temecula, CA, USA; 1:50, Abcam, Cambridge, MA, USA), mouse anti-CCR5 (1:200, R\&D Systems MAB183, Minneapolis, MN, USA) chicken anti-MAP-2 ( $1: 5000$, Abcam), and chicken anti GFAP $(1: 2500$, Abcam). Secondary antibodies were goat anti-rabbit IgG Alexa 594, goat anti-mouse IgG Alexa 488, and goat antichicken IgG Alexa 647 (each at 1:2000, Molecular Probes/Invitrogen, Carlsbad, CA, USA). In triple fluorescence stainings for chemokine receptors, rat microglia was labeled with isolectin B4 conjugated to FITC (1:100, Vector Laboratories). Controls were included in which primary antibodies were either omitted or replaced with irrelevant IgG of the same subclass. Nuclear DNA was stained with H33342. Deconvolution microscopy was performed as described earlier ${ }^{12}$; filters for AMCA, $\mathrm{CY} 3, \mathrm{CY} 5$ and FITC were used for four-color image capture and a 'nearest neighbor' algorithm for deconvolution (Slidebook software, Intelligent Imaging Innovations, Denver, CO, USA).

Calcium imaging. Measurement of $\left[\mathrm{Ca}^{2+}\right]_{i}$ in cerebrocortical cultures was performed using Fura-2/AM as described earlier ${ }^{53}$ with the following modification: all measurements were performed at $37^{\circ} \mathrm{C}$ on a temperature-controlled heated stage in $\mathrm{Mg}^{2+}$-free Hank's balanced saline solution containing $1.8 \mathrm{mM} \mathrm{Ca}^{2+}$ and $5 \mu \mathrm{M}$ glycine. Slidebook software was used for collection and analysis of ratiometric data ( $340 \mathrm{~nm}$ and $380 \mathrm{~nm}$ excitation/510 nm emission), which are shown as change over time relative to baseline value.

Acknowledgements. We thank Dr. Timothy Springer, Center for Blood Research, Harvard Medical School, for CXCR4 KO mice, Dr. Murat Digicaylioglu for helpful discussions, and Lida Sionit, Helen Fang, Julie Wilson and Kenny Venegas for expert technical assistance. We are grateful to Drs. J Han (The Scripps Research Institute) and K Walsh (St. Elizabeth's Medical Center, Tufts University School of Medicine) for providing adenoviral vectors. This work was supported in part by amfAR and by NIH Grants R01 NS050621 (to MK), and P01 HD29587, R01 EY09024, and R01 NS41207 (to SAL). 
1. Choe H, Farzan M, Sun $Y$, Sullivan N, Rollins B, Ponath PD et al. The beta-chemokine receptors CCR3 and CCR5 facilitate infection by primary HIV-1 isolates. Cell 1996; 85 : $1135-1148$.

2. Bleul CC, Farzan M, Choe H, Parolin C, Clark-Lewis I, Sodroski J et al. The lymphocyte chemoattractant SDF-1 is a ligand for LESTR/fusin and blocks HIV-1 entry. Nature 1996; 382: 829-833.

3. He J, Chen Y, Farzan M, Choe H, Ohagen A, Gartner S et al. CCR3 and CCR5 are coreceptors for HIV-1 infection of microglia. Nature 1997; 385: 645-649.

4. Dean M, Carrington M, Winkler C, Huttley GA, Smith MW, Allikmets R et al. Genetic restriction of HIV-1 infection and progression to AIDS by a deletion allele of the CKR5 structural gene. Hemophilia growth and development study, multicenter AIDS cohort study, multicenter hemophilia cohort study, San Francisco city cohort, ALIVE study. Science 1996; 273: 1856-1862.

5. Cocchi F, Devico AL, Garzino-Demo A, Arya SK, Gallo RC, Lusso P. Identification of RANTES, MIP-1 alpha, and MIP-1 beta as the major HIV-suppressive factors produced by CD8+ T cells. Science 1995; 270: 1811-1815.

6. Michael NL, Moore JP. HIV-1 entry inhibitors: evading the issue. Nat Med 1999; 5: 740-742.

7. Kaul M, Garden GA, Lipton SA. Pathways to neuronal injury and apoptosis in HIVassociated dementia. Nature 2001; 410: 988-994

8. Power C, Johnson RT. Neuroimmune and neurovirological aspects of human immunodeficiency virus infection. Adv Virus Res 2001; 56: 389-433.

9. McArthur JC, Haughey N, Gartner S, Conant K, Pardo C, Nath A et al. Human immunodeficiency virus-associated dementia: an evolving disease. J Neurovirol 2003; 9 205-221.

10. Koenig S, Gendelman HE, Orenstein JM, Dal Canto MC, Pezeshkpour GH, Yungbluth M et al. Detection of AIDS virus in macrophages in brain tissue from AIDS patients with encephalopathy. Science 1986; 233: 1089-1093.

11. Kaul M, Lipton SA. Chemokines and activated macrophages in gp120-induced neuronal apoptosis. Proc Natl Acad Sci USA 1999; 96: 8212-8216.

12. Garden GA, Budd SL, Tsai E, Hanson L, Kaul M, D'Emilia DM et al. Caspase cascades in human immunodeficiency virus-associated neurodegeneration. J Neurosci 2002; 22: 4015-4024.

13. Jones G, Power C. Regulation of neural cell survival by HIV-1 infection. Neurobiol Dis 2006; 21: 1-17.

14. Ohagen A, Devitt A, Kunstman KJ, Gorry PR, Rose PP, Korber B et al. Genetic and functional analysis of full-length human immunodeficiency virus type 1 env genes derived from brain and blood of patients with AIDS. J Virol 2003; 77: 12336-12345.

15. Roberts ES, Masliah E, Fox HS. CD163 identifies a unique population of ramified microglia in HIV encephalitis (HIVE). J Neuropathol Exp Neurol 2004; 63: 1255-1264.

16. Giulian D, Vaca K, Noonan CA. Secretion of neurotoxins by mononuclear phagocytes infected with HIV-1. Science 1990; 250: 1593-1596.

17. Giulian D, Wendt E, Vaca K, Noonan CA. The envelope glycoprotein of human immunodeficiency virus type 1 stimulates release of neurotoxins from monocytes. Proc Natl Acad Sci USA 1993; 90: 2769-2773.

18. Chen W, Sulcove J, Frank I, Jaffer S, Ozdener H, Kolson DL. Development of a human neuronal cell model for human immunodeficiency virus (HIV)-infected macrophageinduced neurotoxicity: apoptosis induced by HIV type 1 primary isolates and evidence for involvement of the Bcl-2/Bcl-xL-sensitive intrinsic apoptosis pathway. J Virol 2002; 76 : 9407-9419.

19. Garden GA, Guo W, Jayadev S, Tun C, Balcaitis S, Choi J et al. HIV associated neurodegeneration requires p53 in neurons and microglia. FASEB J 2004; 18: 1141-1143.

20. Gonzalez-Scarano F, Martin-Garcia J. The neuropathogenesis of AIDS. Nat Rev Immuno 2005; 5: 69-81.

21. Rottman JB, Ganley KP, Williams K, Wu L, Mackay CR, Ringler DJ. Cellular localization of the chemokine receptor CCR5. Correlation to cellular targets of HIV-1 infection. Am J Pathol 1997; 151: 1341-1351.

22. Lavi E, Strizki JM, Ulrich AM, Zhang W, Fu L, Wang Q et al. CXCR-4 (fusin), a co-recepto for the type 1 human immunodeficiency virus (HIV-1), is expressed in the human brain in a variety of cell types, including microglia and neurons. Am J Pathol 1997; 151: 1035-1042.

23. Meucci O, Fatatis A, Simen AA, Bushell TJ, Gray PW, Miller RJ. Chemokines regulate hippocampal neuronal signaling and gp120 neurotoxicity. Proc Natl Acad Sci USA 1998; 95: $14500-14505$

24. Hesselgesser J, Horuk R. Chemokine and chemokine receptor expression in the central nervous system. J Neurovirol 1999; 5: 13-26.

25. Bezzi P, Domercq M, Brambilla L, Galli R, Schols D, De Clercq E et al. CXCR4-activated astrocyte glutamate release via TNFalpha: amplification by microglia triggers neurotoxicity. Nat Neurosci 2001; 4: 702-710.

26. Toggas SM, Masliah E, Rockenstein EM, Rall GF, Abraham CR, Mucke L. Central nervous system damage produced by expression of the HIV-1 coat protein gp120 in transgenic mice. Nature 1994; 367: 188-193.

27. Brenneman DE, Westbrook GL, Fitzgerald SP, Ennist DL, Elkins KL, Ruff MR et al. Neuronal cell killing by the envelope protein of HIV and its prevention by vasoactive intestinal peptide. Nature 1988; 335: 639-642.
28. Bachis A, Major EO, Mocchetti I. Brain-derived neurotrophic factor inhibits human immunodeficiency virus-1/gp120-mediated cerebellar granule cell death by preventing gp120 internalization. J Neurosci 2003; 23: 5715-5722.

29. Ma Q, Jones D, Borghesani PR, Segal RA, Nagasawa T, Kishimoto T et al. Impaired Blymphopoiesis, myelopoiesis, and derailed cerebellar neuron migration in CXCR4- and SDF-1-deficient mice. Proc Natl Acad Sci USA 1998; 95: 9448-9453.

30. Huffnagle GB, McNeil LK, McDonald RA, Murphy JW, Toews GB, Maeda $\mathrm{N}$ et al. Cutting edge: role of $\mathrm{C}-\mathrm{C}$ chemokine receptor 5 in organ-specific and innate immunity to Cryptococcus neoformans. J Immunol 1999; 163: 4642-4646.

31. Bonfoco E, Krainc D, Ankarcrona M, Nicotera P, Lipton SA. Apoptosis and necrosis: two distinct events induced, respectively, by mild and intense insults with $N$-methyl-D-aspartate or nitric oxide/superoxide in cortical cell cultures. Proc Natl Acad Sci USA 1995; 92: 71627166 .

32. Blanpain C, Migeotte I, Lee B, Vakili J, Doranz BJ, Govaerts C et al. CCR5 binds multiple CC-chemokines: MCP-3 acts as a natural antagonist. Blood 1999; 94: 1899-1905.

33. Xia Z, Dickens M, Raingeaud J, Davis RJ, Greenberg ME. Opposing effects of ERK and JNK-p38 MAP kinases on apoptosis. Science 1995; 270: 1326-1331.

34. Bhat NR, Zhang P, Lee JC, Hogan EL. Extracellular signal-regulated kinase and p38 subgroups of mitogen-activated protein kinases regulate inducible nitric oxide synthase and tumor necrosis factor-alpha gene expression in endotoxin-stimulated primary glial cultures. J Neurosci 1998; 18: 1633-1641.

35. Koistinaho M, Kettunen Ml, Goldsteins G, Keinanen R, Salminen A, Ort M et al. Betaamyloid precursor protein transgenic mice that harbor diffuse $A$ beta deposits but do not form plaques show increased ischemic vulnerability: role of inflammation. Proc Natl Acad Sci USA 2002; 99: 1610-1615

36. Kaul M, Lipton SA. Knock out of HIV-1 coreceptors attenuates neuronal apoptosis induced by HIV envelope glycoprotein gp120. Soc Neurosci Abstr 2001; 27: 678.8.

37. O'Donnell LA, Agrawal A, Jordan-Sciutto KL, Dichter MA, Lynch DR, Kolson DL. Human immunodeficiency virus (HIV)-induced neurotoxicity: roles for the NMDA receptor subtypes. J Neurosci 2006; 26: 981-990.

38. Digicaylioglu M, Garden G, Timberlake S, Fletcher L, Lipton SA. Acute neuroprotective synergy of erythropoietin and insulin-like growth factor I. Proc Natl Acad Sci USA 2004; 101: 9855-9860.

39. Honczarenko M, Le Y, Glodek AM, Majka M, Campbell JJ, Ratajczak MZ et al. CCR5binding chemokines modulate CXCL12 (SDF-1)-induced responses of progenitor B cells in human bone marrow through heterologous desensitization of the CXCR4 chemokine receptor. Blood 2002; 100: 2321-2329.

40. Hecht I, Cahalon L, Hershkoviz R, Lahat A, Franitza S, Lider O. Heterologous desensitization of $\mathrm{T}$ cell functions by CCR5 and CXCR4 ligands: inhibition of cellular signaling, adhesion and chemotaxis. Int Immunol 2003; 15: 29-38.

41. Bruno V, Copani A, Besong G, Scoto G, Nicoletti F. Neuroprotective activity of chemokines against $\mathrm{N}$-methyl-D-aspartate or beta-amyloid-induced toxicity in culture. Eur J Pharmacol 2000; 399: 117-121.

42. Letendre SL, Lanier ER, McCutchan JA. Cerebrospinal fluid beta chemokine concentrations in neurocognitively impaired individuals infected with human immunodeficiency virus type 1. J Infect Dis 1999; 180: 310-319.

43. Agrawal L, Lu X, Qingwen J, VanHorn-Ali Z, Nicolescu IV, McDermott DH et al. Role for CCR5Delta32 protein in resistance to R5, R5X4, and X4 human immunodeficiency virus type 1 in primary CD4+ cells. J Virol 2004; 78: 2277-2287.

44. Mukherjee PK, DeCoster MA, Campbell FZ, Davis RJ, Bazan NG. Glutamate receptor signaling interplay modulates stress-sensitive mitogen-activated protein kinases and neuronal cell death. J Biol Chem 1999; 274: 6493-6498.

45. Lu M, Grove EA, Miller RJ. Abnormal development of the hippocampal dentate gyrus in mice lacking the CXCR4 chemokine receptor. Proc Natl Acad Sci USA 2002: 99: 7090-7095.

46. Tran PB, Miller RJ. Chemokine receptors: signposts to brain development and disease. Nat Rev Neurosci 2003; 4: 444-455.

47. Choi DW, Maulucci-Gedde M, Kriegstein AR. Glutamate neurotoxicity in cortical cell culture. J Neurosci 1987; 7: 357-368.

48. Lei SZ, Pan ZH, Aggarwal SK, Chen HS, Hartman J, Sucher NJ et al. Effect of nitric oxide production on the redox modulatory site of the NMDA receptor-channel complex. Neuron 1992; 8: 1087-1099.

49. Lipton SA, Choi YB, Pan ZH, Lei SZ, Chen HS, Sucher NJ et al. A redox-based mechanism for the neuroprotective and neurodestructive effects of nitric oxide and related nitrosocompounds. Nature 1993; 364: 626-632.

50. Fujio $\mathrm{Y}$, Walsh K. Akt mediates cytoprotection of endothelial cells by vascular endothelia growth factor in an anchorage-dependent manner. J Biol Chem 1999; 274: 16349-16354.

51. Han J, Jiang Y, Li Z, Kravchenko VV, Ulevitch RJ. Activation of the transcription factor MEF2C by the MAP kinase p38 in inflammation. Nature 1997; 386: 296-299.

52. Zhao M, New L, Kravchenko VV, Kato Y, Gram H, Di Padova F et al. Regulation of the MEF2 family of transcription factors by p38. Mol Cell Biol 1999; 19: 21-30.

53. Tenneti L, D'Emilia DM, Troy CM, Lipton SA. Role of caspases in N-methyl-D-aspartateinduced apoptosis in cerebrocortical neurons. J Neurochem 1998; 71: 946-959. 